\title{
APPLICATION OF GIS AND GEOSTATISTICS TO CHARACTERIZE SPATIAL VARIATION OF SOIL FLUORIDE ON HANG-JIA-HU PLAIN, CHINA
}

\author{
Zhengmiao Xie * , Jing Li, Weihong Wu \\ Institute of Environmental Science and Engineering, Hangzhou Dianzi University, Hangzhou \\ 310018, P. R. China \\ * Corresponding author, Tel: +86-571-86878583; Fax: +86-571-86919155; Email address: \\ zhmxie@sina.com
}

Abstract: $\quad$ Spatial variability of soil fluoride in the plough layer $(0-20 \mathrm{~cm})$ of paddy soil from Hang-Jia-Hu Plain of Zhejiang Province in China was studied using geostatistical analysis and GIS technique. The results of Semivariograms analysis showed that two forms of soil fluoride were correlated in a given spatial range, and total fluoride (T-F) was controlled by intrinsic factors of parent material, relief and soil type, whereas water-soluble fluoride (Ws-F) was greatly affected by extrinsic factors such as fertilization and soil management. Kriging method was applied to estimate the unobserved points and their distribution maps were obtained, which indicated that the concentrations of soil T-F and Ws-F had a close relationship with parent material, $\mathrm{pH}$ value, organic matter, cation exchange capacity content and soil texture. The main contents distribution of T-F and Ws-F were $200-300 \mathrm{mg} \mathrm{kg}^{-1}$, $0.5-1.0 \mathrm{mg} \mathrm{kg}^{-1}$ in the studied area, respectively. And what is more, the range of T-F contents in soil was as low as less than $100 \mathrm{mg} \mathrm{kg}^{-1}$ in Yu-hang area accounting for $23.7 \%$ area scale. The range of fluoride contents in the soils from central and eastern parts of Hang-Jia-Hu Plain was higher than that from the western part. The accumulation of fluoride contents in soil was lower in the whole studied area, suggesting that local fluoride epidemic such as dental caries due to lack of fluoride should be prevented by using fluoride-containing toothpaste.

Keywords: Fluoride, Geostatistics, GIS, Spatial variation, Kriging method

Xie, Z., Li, J. and Wu, W., 2008, in IFIP International Federation for Information Processing, Volume 258; Computer and Computing Technologies in Agriculture, Vol. 1; Daoliang Li; (Boston: Springer), pp. 253-266. 


\section{INTRODUCTION}

Fluoride (F) is regarded as an essential trace element, primarily because of its benefits to dental health and its suggested role in maintaining the integrity of bone (Underwood and Mertz 1987; Wheeler and Fell 1983). A small amount of fluoride is beneficial in the prevention of dental caries. It has also been used to treat osteoporosis (Fung et al. 1999). However, excessive fluoride is built up in the apatite ctystals in teeth and bones and reduces their solubility (Fejerskov et al. 1994; Fung et al. 1999). Traditionally, excessive fluoride has been connected with high intake of fluoride through drinking water and food (Marian et al. 1997; Singh and Dass 1993), but water and food take up fluoride from soil and accumulate it in human body finally though food web (Marian et al. 1997), unbalance of fluoride in the human body can cause diseases of teeth and bones (Fung et al. 1999; Xie et al. 2001). Therefore, increasing attention should be paid to soil fluoride quality.

In recent years, geostatistics has been proved as a successful method to study distributions of soil heavy metals (Atteia et al. 1994; Steiger et al. 1996; White et al. 1997; Yu et al. 2001; Romic and Romic 2003) and soil nutrient (Tsegaye and Robert 1998; Fisher et al. 1998; Cahn et al. 1994). However, most of the previous geostatistical studies were focused on data at small scale (Wang 1999; Goovaerts 1999). With the development of Geographical Information System (GIS), GIS can integrate attribute data with geographical data of system variables, which makes the application of geostatistics technique for large spatial scale more convenient (Steiger 1996; Bai et al. 1999; Mendonca Santos et al. 2000). Geostatistics and GIS are becoming indispensable in characterizing and summarizing spatial information in large regions to provide quantitative support to decision and policy making for soil, agricultural and natural resources management (Wang 1999; Guo et al. 2000; Liu et al. 2003).

However, the papers on soil fluoride was less relatively, and that according to local fluoride epidemic has evolved in response to high soil concentrations of fluoride in contaminated sites (Horner and Bell 1995), so previous study had stressed on the fluoride contents in contaminated soil too and there is minimum information on spatial distributions of soil fluoride in paddy fields, and less information in a large scale (Geeson et al. 1998; Li et al. 2004). In this paper, we applied geostatistics combined with GIS to (1) analyze the spatial dependency and explain the variation mechanism of soil fluoride in the paddy soils; (2) map the spatial distribution of soil fluoride in the soil; (3) provide information for environmental monitoring and evaluation in Hang-Jia-Hu Plain. 


\section{MATERIALS AND METHODS}

\subsection{Study area}

Hang-Jia-Hu Plain is in the center of Hangzhou-Jiaxing-Huzhou in the North of Zhejiang Province in the southeast of China, including Jiaxing, Pinghu, Tongxiang, Haining, Jiashan, Haiyan, Hangzhou, Yuhang, Deqing, Changxing, Anji, Huzhou and part of Lin'an, 13 regions altogether. It boders the Hangzhou Gulf, a part of the East China Sea (Fig. 1). It is an coastal and lacustrine alluvial plain with an altitude of $3-7 \mathrm{~m}$ above sea level. The climate of the area is subtropical humid monsoonal climate and has abundant rain capacity, the average rang of temperature and rainfall density are $16-19^{\circ} \mathrm{C}$ and $1200-1300 \mathrm{~mm}$ every year, respectively. It is densely dotted with drainage ditches that form a network waterway. Rice (Oryza Satiya) has been dominant crop in the studied area, a large part of the area has acidic paddy soil.

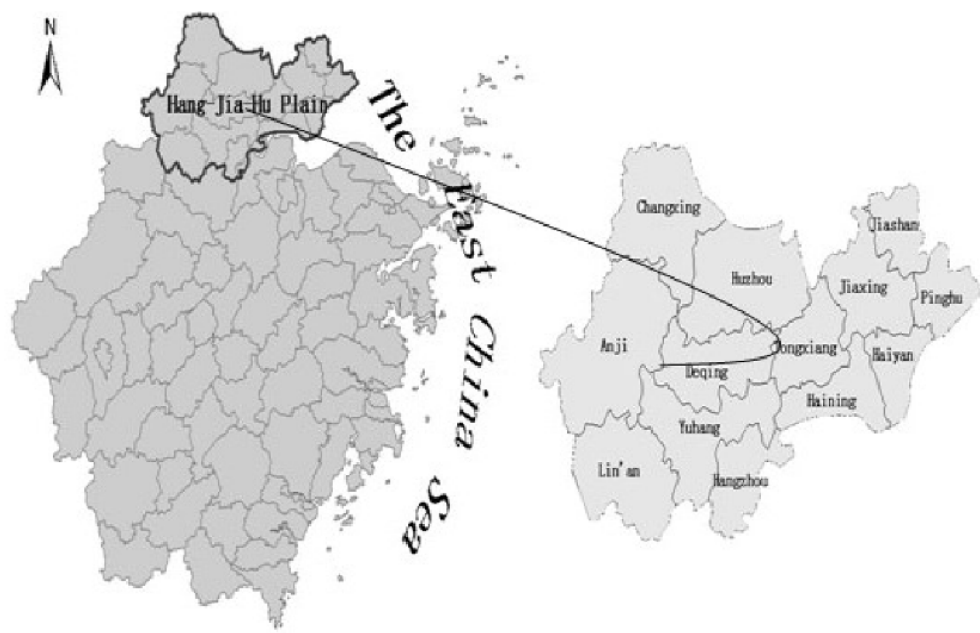

Fig. 1. Location of the study area

\subsection{Soil sampling and analysis}

Soil samples were taken from over 460 locations within Hang-Jia-Hu Plain in April 2000. Sampling points are presented in Fig. 2. Because there are more low mountains and hills in Anji, Lin'an and Deqing region in the western of Hang-Jia-Hu Plain, the sampling points were sparse comparatively. 


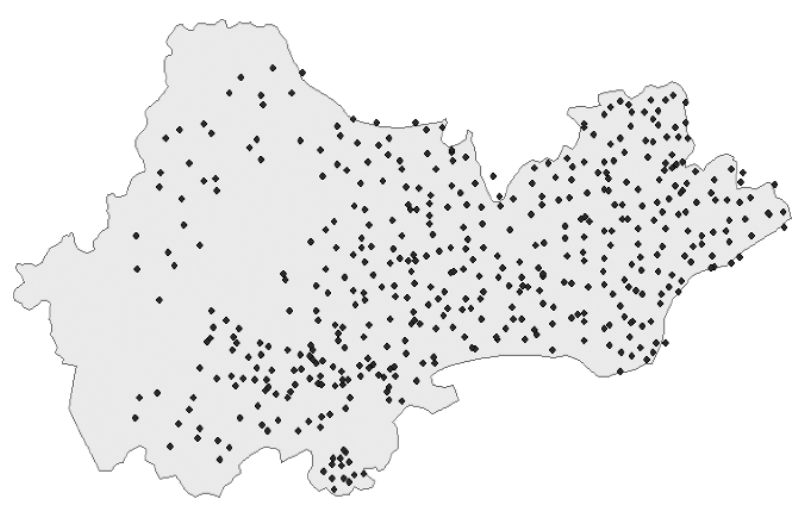

Fig. 2. Distribution of sampling sites in Hang-Jia-Hu Plain

Some characteristics of the soils are presented in Table 1. Pipette method was used to determine the particle composition according to the International System. Soil $\mathrm{pH}$ value, organic matter $(\mathrm{OM})$ and cation exchange capacity (CEC) were tested according to the conventional methods (Nanjing Agricultural University 1981).

Table 1. Basic properties of the soil samples in Hang-Jia-Hu Plain

\begin{tabular}{lcccccc}
\hline & & & & \multicolumn{3}{c}{ Particle composition (\%) } \\
\cline { 5 - 7 } & $\begin{array}{c}\mathrm{pH} \\
\left(\mathrm{H}_{2} \mathrm{O}\right)\end{array}$ & $\begin{array}{c}\mathrm{OM} \\
\left(\mathrm{g} \mathrm{kg}^{-1}\right)\end{array}$ & $\begin{array}{c}\mathrm{CEC} \\
\left(\mathrm{cmol} \mathrm{kg}^{-1}\right)\end{array}$ & $<0.002 \mathrm{~mm}$ & $0.002 \sim 0.05 \mathrm{~mm}$ & $0.05 \sim 2 \mathrm{~mm}$ \\
\hline Range & $4.1 \sim 8.3$ & $10.9 \sim 61.4$ & $5.3 \sim 24.8$ & $4.9 \sim 23.5$ & $36.4 \sim 80.2$ & $5.1 \sim 51.4$ \\
Mean & 5.8 & 34.0 & 14.8 & 14.2 & 69.0 & 16.7 \\
S.D. & 0.7 & 9.1 & 3.9 & 2.8 & 7.0 & 7.6 \\
CV\% & 12.0 & 26.7 & 26.3 & 19.9 & 10.1 & 45.2 \\
\hline
\end{tabular}

S.D., standard deviation; CV, coefficient of variation

For total fluoride (T-F) analysis, direct determination of total fluoride in samples was made using a $\mathrm{NaOH}$ fusion-selective ion electrode technique (Baker 1972; Villa 1979). $0.25 \mathrm{~g}$ of sample were passed through a 100-mesh sieve and put into a 50-ml nickel crucible $3.0 \mathrm{ml}$ of $16.75 \mathrm{~mol} / \mathrm{l} \mathrm{NaOH}$ solution, then placed in an oven at $150^{\circ} \mathrm{C}$ for $1 \mathrm{~h}$ until dry. The crucible with sample was then placed in a Muffle furnace. The temperature was raised to $600^{\circ} \mathrm{C}$. The samples were fused after $30 \mathrm{~min}$ at this temperature. After the samples had been removed from the muffle furnace and cooled, $5 \mathrm{ml}$ of de-ionised water was added and then heated slightly to facilitate the dissolution of the fused soil with 
sodium hydroxide. Then, $4 \mathrm{ml}$ of concentrated $\mathrm{HCl}$ were added slowly, with stirring, to adjust $\mathrm{pH}$ to $8-9$ (checked with $\mathrm{pH}$ test paper). The cooled dissolved sample was transferred to a 50-ml volumetric flask, diluted with distilled water to volume, and then filtered through dry filter paper. The filtrate was used for the determination of fluoride. A reagent blank was produced.

Water-soluble fluoride (Ws-F) was extracted by ratio of 1:5 soil to water. Ten grams of soil passed through a 60-mesh sieve and 50-ml distilled water were placed in 60-mesh sieve and 50-ml distilled water were placed in polyethylene bottles, shaken for $0.5 \mathrm{~h}$ on an end-over-end shaker, then centrifuged. Then fluoride levels were measured by ion-specific electrode potentiometer (Xie et al. 2003).

\subsection{Data analysis}

Distribution of soil fluoride element were characterized using the Kolmogrov-Smirnov (K-S) test for goodness-of-fit (Sokal and Rohlf 1981) to ensure that the distribution could be validly applied to data sets. Descriptive statistics, including the range, mean, standard deviation (SD) and coefficient of variation (CV), were determined for each set of data using the statistical analysis system (SPSS) and correlation analysis was conducted.

Geostatistics were used to estimate and map soils in unsampled areas (Goovaerts 1999). Among the geostatistical techniques, Kriging is a linear interpolation procedure that provides a best linear unbiased estimation for quantities that vary in space. The procedure provides estimates at unsampled sites. Kriging's estimates are calculated as weighted sums of the adjacent sampled concentrations. That is, if data appear to be highly continuous in space, the points closer to those estimated receive higher weights than those farther away (Cressie 1990).

In this study, spatial patterns of soil fluoride element were determined using the geostatistical analysis. Semivariograms were developed to evaluate the degree of spatial continuity of soil fluoride element among data points and to establish a range of spatial dependence for each soil soil fluoride element using GS+3.1 software. Information generated through variogram was used to calculate sample-weighted factors for spatial interpolation by a Kriging procedure (Isaaks and Srivastava 1989) using Arc/Info8.1 and Arcview3.2 software based on GIS technique from ESRI company. 
3. RESULTS AND DISCUSION

\subsection{Summary statistics}

Fig. 3 displays the histograms (a) on the orginal scales and (b) as common logarithms $\left(\log _{10}\right)$ of T-F and Ws-F. The distributions of T-F and Ws-F had long upper tails, and there are several data that might be considered as outliers. Some transformation was desirable for further analysis. Taking logarithms achieved approximate symmetry (Fig. 3(b)) and allowed a confident comparison of mean value for different forms of land use. It also brought the apparent outliers of T-F and Ws-F within the distributions and showed that they should not be treated as exceptional. The statistical results using the Kolmogrov-Smirnov (K-S) test indicated that the soil T-F was more nearly normally distributed than logarithm transformed, but the distribution of Ws-F remained more strongly peaked than normal (leptokurtic). Taking logarithms for Ws-F brought the skewness to only 0.23 and the kurtosis was -0.14 . Clearly, its distribution is close to logarithm normal distribution.

(a)
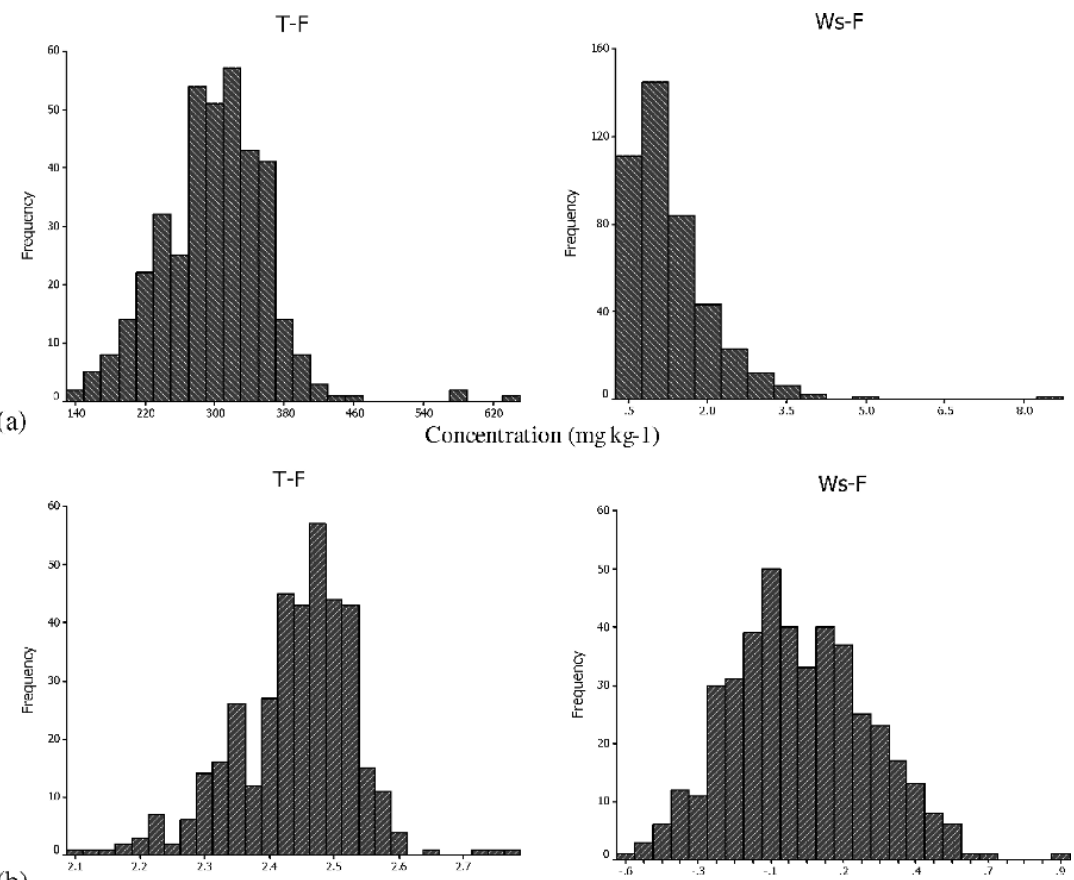

(b)

Log concentration (mg kg-1)

Fig. 3. Histograms (a) on original scales and (b) after transforming to logarithms 


\subsection{Geostatistical analysis}

The concentrations of T-F and Ws-F were transformed to standard normal deviates by Hermite polomomaials, as described above. For T-F and Ws-F all the data were included. Fig. 4 presented the semivariogram and fitted models for fluoride element. The attributes of the semivariograms for soil fluoride were summarized in Table 2.
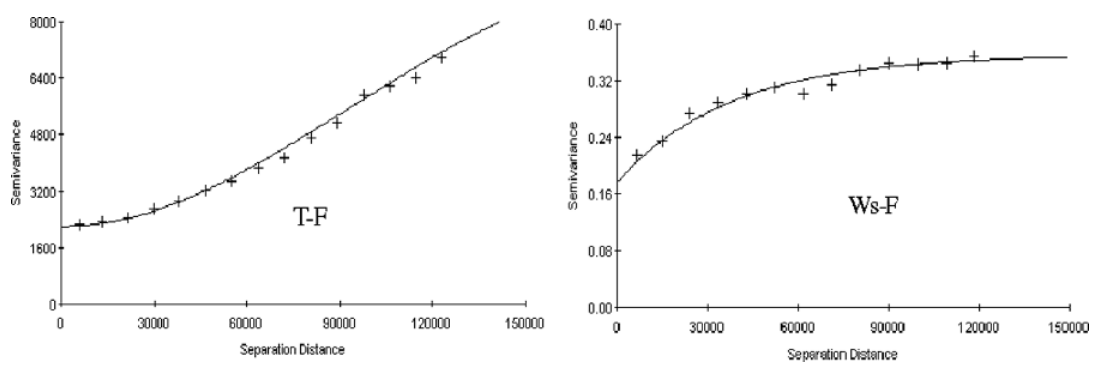

Fig. 4. Experimental semivariograms of soil fluoride element with fitted models

Table 2. Best-fitted semivariogram models of soil $\mathrm{F}$ and corresponding parameters

\begin{tabular}{ccccccc}
\hline F Element & Model & $\mathrm{C}_{0}$ & $\mathrm{C}_{0}+\mathrm{C}_{1}$ & Range $(\mathrm{km})$ & $\mathrm{C}_{0} /\left(\mathrm{C}_{0}+\mathrm{C}_{1}\right)$ & $\mathrm{R}^{2}$ \\
T-F & Gaussian & 2200 & 9510 & 632.7 & $23.1 \%$ & 0.995 \\
Ws-F & Exponential & 0.178 & 0.357 & 42.9 & $49.9 \%$ & 0.960 \\
\hline
\end{tabular}

Nugget variance $\left(\mathrm{C}_{0}\right)$ represents the experimental error and field variation within the minimum sampling spacing. The Nug/Sill ratio $\left(\mathrm{C}_{0} /\left(\mathrm{C}_{0}+\mathrm{C}_{1}\right)\right)$ can be regarded as a criterion to classify the spatial dependence of soil properties. If the ratio is less than $25 \%$, the variable has strong spatial dependence; between $25 \%$ and $75 \%$, the variable has moderate spatial dependence; and greater than $75 \%$, the variable shows only weak spatial dependence (Chien et al. 1997). The spatial variability of soil properties may be affected by intrinsic (soil formation factors, such as soil parent materials) and extrinsic factors (soil management practices, such as fertilization). Usually, strong spatial dependence of soil properties can be attributed to intrinsic factors, and weak spatial dependence can be attributed to extrinsic factors (Cambardella et al. 1994). Range is the distance over which spatial dependence. Regression coefficient $\left(\mathrm{R}^{2}\right)$ provides an indication of how the model fits the variogram data. The higher the regression coefficient, the better the model fits ( $\mathrm{Hu}$ et al. 2004). 
The semivariograms results suggested that the semivariagrams of T-F was well fitted for the gaussian model, while semivariagrams for logarithm conversion value of soil Ws-F was well fitted for exponential model. And their Nug/Sill ratios were $23.1 \%$ and $49.9 \%$, respectively. The results suggested that T-F had strong spatial dependence, its spatial variabilities were mainly controlled by intrinsic factors such as parent material, relieves and soil types; Ws-F had moderate spatial dependence, mainly controlled by intrinsic factors and extrinsic factors. The ranges for T-F and Ws-F were $632.7 \mathrm{~km}$ and $42.9 \mathrm{~km}$, respectively, indicating $\mathrm{T}-\mathrm{F}$ in soil was mainly affected by parent material. The $\mathrm{R}^{2}$ about T-F and Ws-F in soil were both over 0.9 , indicating the selective model better fitted.

\subsection{Spatial distributions}

Fig. 5 shows the spatial patterns of T-F and Ws-F in soil generated from their semivariagrams. In order to know easily the distribution of soil T-F and Ws-F in Hang-Jia-Hu Plain, according to a guideline in practical level of soil and the area proportion were analysed (Table 3). To understand the effect of Parent material and soil property on T-F and Ws-F content, main parent materials with corresponding average soil property and soil $\mathrm{F}$ contents in 13 regions of Hang-Jia-Hu Plain were listed (Table 4), the correlativity between them and soil properties was analyzed (Table 5 and Table 6).
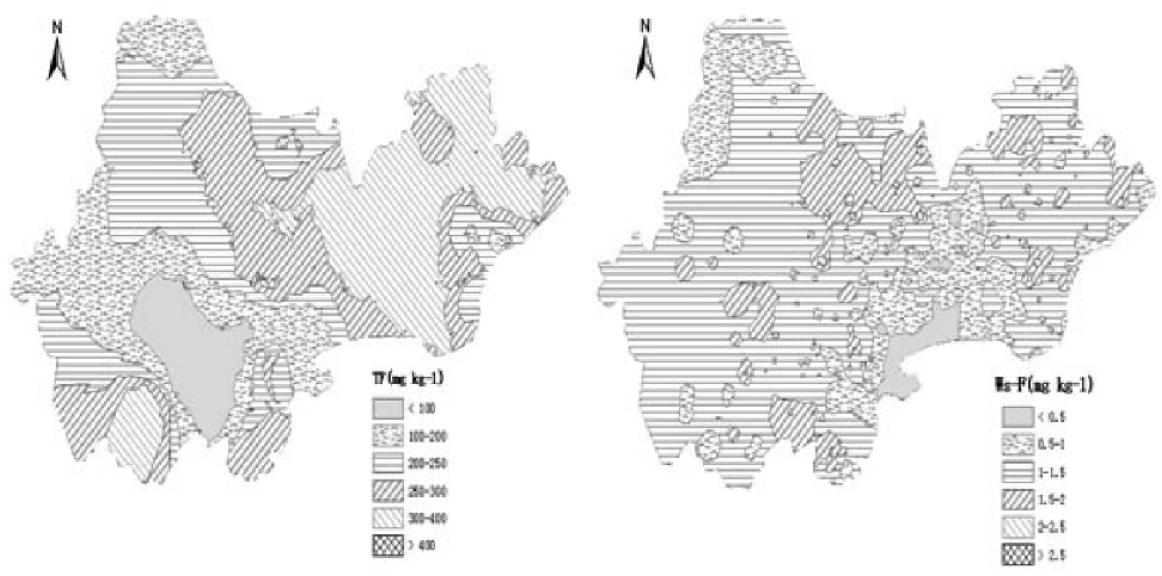

Fig. 5. Filled contour maps produced by ordinary Kriging of T-F and Ws-F in soil 
Table 3. The guideline and the area ratio of T-F and Ws-F produced by ordinary Kriging

\begin{tabular}{llllll}
\hline T-F & \multicolumn{5}{c}{ Ws-F } \\
\hline Guideline & Area $\left(\mathrm{km}^{2}\right)$ & Ratio $(\%)$ & Guideline & Area $\left(\mathrm{km}^{2}\right)$ & Ratio $(\%)$ \\
\hline$<100$ & 1019.0 & 8.1 & $<0.5$ & 213.8 & 1.7 \\
$100-200$ & 1959.0 & 15.6 & $0.5-1$ & 6475.5 & 51.4 \\
$200-250$ & 3606.3 & 28.6 & $1-1.5$ & 4419.4 & 35.1 \\
$250-300$ & 2902.6 & 23 & $1.5-2$ & 1319.5 & 10.5 \\
$300-400$ & 3108.4 & 24.7 & $2-2.5$ & 167.1 & 1.3 \\
$>400$ & & & $>2.5$ & & \\
\hline
\end{tabular}

Table 4. Main parent material and corresponding average soil property and soil $\mathrm{F}$ contents in 13 regions of Hang-Jia-Hu Plain

\begin{tabular}{|c|c|c|c|c|c|c|c|c|c|c|}
\hline \multirow[b]{2}{*}{ Code } & \multirow[b]{2}{*}{ Region } & \multirow[b]{2}{*}{ Parent material } & \multirow[b]{2}{*}{$\begin{array}{l}\mathrm{pH} \\
\left(\mathrm{H}_{2} \mathrm{O}\right)\end{array}$} & \multirow[b]{2}{*}{$\begin{array}{l}\mathrm{OM} \\
\left(\mathrm{g} \mathrm{kg}^{-1}\right)\end{array}$} & \multirow[b]{2}{*}{$\begin{array}{l}\text { CEC } \\
\left(\mathrm{cmol} \mathrm{kg}^{-1}\right)\end{array}$} & \multicolumn{3}{|c|}{ Particle composition(\%) } & \multirow[b]{2}{*}{$\mathrm{T}-\mathrm{F}$} & \multirow[b]{2}{*}{ Ws-F } \\
\hline & & & & & & $<0.002 \mathrm{~mm}$ & $0.002-0.05 \mathrm{~mm}$ & $0.05-2 \mathrm{~mm}$ & & \\
\hline 1 & Jiaxing & $\begin{array}{l}\text { River deposit, lake warp } \\
\text { lake deposit, offing }\end{array}$ & 5.80 & 36.92 & 18.65 & 14.58 & 70.32 & 15.19 & 332.94 & 1.07 \\
\hline 2 & Pinghu & deposit & 5.61 & 35.06 & 18.01 & 14.55 & 73.07 & 12.38 & 329.05 & 1.33 \\
\hline 3 & Tongxiang & $\begin{array}{l}\text { Fluvio-marine deposit, } \\
\text { River deposit }\end{array}$ & 6.32 & 28.44 & 15.67 & 12.85 & 72.77 & 14.36 & 338.51 & 1.78 \\
\hline 4 & Haining & $\begin{array}{l}\text { River deposit, marine } \\
\text { deposit }\end{array}$ & 6.05 & 24.01 & 14.04 & 13.63 & 73.74 & 12.64 & 294.16 & 1.50 \\
\hline 5 & Jiashan & River deposit, lake warp & 5.72 & 37.08 & 18.33 & 14.61 & 67.37 & 18.04 & 338.92 & 1.41 \\
\hline 6 & Haiyan & $\begin{array}{l}\text { Ancient lake warp, } \\
\text { fluvio-marine deposit }\end{array}$ & 5.52 & 35.27 & 15.69 & 14.32 & 72.61 & 13.07 & 298.07 & 1.49 \\
\hline 7 & Hangzhou & $\begin{array}{l}\text { Old-river alluvium, } \\
\text { shallow-sea alluvium }\end{array}$ & 6.07 & 32.80 & 11.83 & 12.19 & 68.26 & 19.55 & 259.81 & 1.64 \\
\hline 8 & Yuhang & transported redeposit & 5.64 & 33.83 & 12.29 & 14.56 & 63.98 & 21.46 & 255.34 & 1.08 \\
\hline 9 & Lin'an & Diluvial alluvium & 5.84 & 33.87 & 10.22 & 17.18 & 56.72 & 26.13 & 316.32 & 0.88 \\
\hline 10 & Deqing & Lagoonal lake wrap & 5.67 & 34.52 & 14.41 & 15.23 & 69.31 & 15.45 & 288.00 & 0.92 \\
\hline 11 & Changxing & Lagoonal lake wrap & 5.41 & 31.05 & 13.24 & 15.84 & 65.06 & 19.14 & 223.06 & 0.74 \\
\hline 12 & Anji & $\begin{array}{l}\text { Yellow and red soil } \\
\text { redidual deposit } \\
\text { Lagoonal lake wrap, }\end{array}$ & 5.19 & 33.42 & 9.20 & 15.81 & 63.26 & 20.93 & 211.97 & 0.57 \\
\hline 13 & Huzhou & Fluvio-marine deposit & 6.03 & 40.58 & 14.63 & 13.77 & 70.97 & 15.26 & 277.44 & 1.36 \\
\hline
\end{tabular}

Table 5. Correlation coefficients among $\mathrm{pH}$, organic matter, CEC, clay and $\mathrm{F}$ elements

\begin{tabular}{|c|c|c|c|c|c|c|c|c|}
\hline & \multirow[b]{2}{*}{$\mathrm{pH}\left(\mathrm{H}^{2} \mathrm{O}\right)$} & \multirow{2}{*}{$\begin{array}{l}\mathrm{OM} \\
\left(\mathrm{g} \mathrm{kg}^{-1}\right)\end{array}$} & \multirow{2}{*}{$\begin{array}{l}\text { CEC } \\
\left(\mathrm{cmol} \mathrm{kg}^{-1}\right)\end{array}$} & \multicolumn{3}{|c|}{ Particle composition $(\%)$} & \multirow{2}{*}{$\begin{array}{l}\text { T-F } \\
\left(\mathrm{mg} \mathrm{kg}^{-1}\right)\end{array}$} & \multirow{2}{*}{$\begin{array}{l}\text { Ws-F } \\
\left(\mathrm{mg} \mathrm{kg}^{-1}\right)\end{array}$} \\
\hline & & & & $<0.002 \mathrm{~mm}$ & $0.002-0.05 \mathrm{~mm}$ & $0.05-2 \mathrm{~mm}$ & & \\
\hline $\mathrm{pH}$ & 1 & & & & & & & \\
\hline $\mathrm{OM}$ & 0.019 & 1 & & & & & & \\
\hline CEC & $0.113^{*}$ & $0.388^{* *}$ & 1 & & & & & \\
\hline$<0.002 \mathrm{~mm}$ & $-0.140^{* *}$ & $0.359^{* *}$ & 0.359 & 1 & & & & \\
\hline $0.002-0.05 \mathrm{~mm}$ & $0.142^{* *}$ & $-0.142^{* *}$ & 0.241 & 0.023 & 1 & & & \\
\hline $0.05-2 \mathrm{~mm}$ & -0.079 & -0.003 & -0.355 & $-0.396^{* *}$ & $-0.927^{* *}$ & 1 & & \\
\hline $\mathrm{T}-\mathrm{F}$ & $0.193^{* *}$ & $0.186^{* *}$ & 0.580 & $0.274^{* *}$ & 0.054 & $-0.160^{* *}$ & 1 & \\
\hline Ws-F & $0.612^{* *}$ & -0.050 & 0.070 & $-0.234^{* *}$ & $0.159^{* *}$ & -0.060 & $0.169^{* *}$ & 1 \\
\hline
\end{tabular}

${ }^{*} p<0.05 ;{ }^{* *} p<0.01$ 
Table 6. Stepwise regression of F elements in tested soil in Hang-Jia-Hu Plain

\begin{tabular}{lccc}
\hline Regression equation of T-F and Ws-F & \multicolumn{3}{c}{ Parameters of regression equation } \\
\cline { 2 - 4 } & Multiple correlation coefficient & F value & Significant level \\
\hline$Y_{\mathrm{T}-\mathrm{F}}=26.584+19.253 X_{1}-6.473 X_{2}+8.372 X_{3}+3.989 X_{4}$ & 0.661 & 52.37 & $p<0.05$ \\
$Y_{\mathrm{Ws}-\mathrm{F}}=-2.551+0.661 X_{1}-0.049 X_{4}+0.010 X_{5}$ & 0.628 & 86.26 & $p<0.05$ \\
\hline$X_{l}, \mathrm{pH}$ value; $X_{2}$, organic matter; $X_{3}, \mathrm{CEC}$ content; $X_{4}$, clay fraction $(<0.002 \mathrm{~mm}) ; X_{5}$, silt fraction & \\
$(0.002-0.05 \mathrm{~mm}) ; \mathrm{X} 6$, sand fraction $(0.05-2 \mathrm{~mm})$ & &
\end{tabular}

The content distribution of T-F in the plough layer $(0-20 \mathrm{~cm})$ of paddy soils in Hang-Jia-Hu Plain was the eastern part > central part > western part. As a whole, however, the concentration of soil T-F in Hang-Jia-Hu Plain was comparatively lower, had $2978 \mathrm{~km}^{2}$ area accounting for $23.7 \%$ in the studied area and was lower than the fluoride content in soil which is $200 \mathrm{mg}$ $\mathrm{kg}^{-1}$ on average in the world (China Environmental Monitoring General Station, 1990). The main range of T-F content was $200-300 \mathrm{mg} \mathrm{kg}^{-1}$ accounting for $51.6 \%$ in the studied area and lower than the fluoride content in soil which is $478 \mathrm{mg} \mathrm{kg}^{-1}$ on average in China (China Environmental Monitoring General Station, 1990). The average range of soil T-F concentration in Anji, Deqing, Hangzhou zone was $100-200 \mathrm{mg} \mathrm{kg}^{-1}$, especially the range of T-F contents in soil was as low as less than $100 \mathrm{mg}$ $\mathrm{kg}^{-1}$ in Yu-hang area. The range of T-F contents in soil in Jiaxing, Jiashan, Pinghu zone and part area of Lin'an was exceed $300 \mathrm{mg} \mathrm{kg}^{-1}$. The characteristic distribution of soil T-F was mainly associated with each parent material distribution in the 13 regions of Hang-Jia-Hu Plain, the contents of soil T-F developing from river deposit and lake warp exceeded others, yellow and red soil redidual deposit had the least soil T-F contents. And the distribution rule of soil T-F was as same as $\mathrm{pH}$ value, organic matter and clay fraction $(<0.002 \mathrm{~mm})$, which was in positive correlation with them, and stepwise regression of soil T-F indicating the concentration of soil T-F was mainly affected by $\mathrm{pH}$ value and CEC contents. The studied results were the same as the previous studied papers. Although fertilization and irrigation can also add up soil fluoride contents, the less effect on it for the less source.

The content distribution of Ws-F in the plough layer $(0-20 \mathrm{~cm})$ of paddy soils in Hang-Jia-Hu Plain was the central part > eastern part > western part. The main range of Ws-F content was $0.5-1.0 \mathrm{mg} \mathrm{kg}^{-1}$ in the whole studied zone accounting for $51.4 \%$ and centralized in the western area. The average range of soil Ws-F concentration in part area of Anji and Lin'an was less than the water-soluble fluoride content in uncontaminated soil surface layer which is $0.5 \mathrm{mg} \mathrm{kg}^{-1}$ on average in the world (China Environmental Monitoring General Station, 1990) and only had $213.8 \mathrm{~km}^{2}$ area, where had the lowest $\mathrm{pH}$ value and CEC content in the whole area. The content of 
Ws-F was comparatively higher in the central and eastern zone, especially in part area of Tongxiang and Hangzhou, the range of Ws-F contents in soil was $2.0-2.5 \mathrm{mg} \mathrm{kg}^{-1}$, where had the highest $\mathrm{pH}$ value and the lowest organic matter in the whole zone. Which was mainly connected with different parent material distribution in this 13 region of Hang-Jia-Hu Plain too. And the content distribution rule of Ws-F was as same as that of $\mathrm{pH}$ value and CEC content and which was in positive correlation with them, in contrast to that of organic matter and clay fraction $(<0.002 \mathrm{~mm})$ which was in negative correlation with them, and stepwise regression of soil Ws-F indicating the concentration of soil Ws-F was mainly affected by $\mathrm{pH}$ value.

The results of this study confirm previous reports indicating that the fluoride concentration has connected with a number of factors such as soil type, parent material, $\mathrm{pH}$ value and farm management. Further research should be carried out to study the relationship between the fluoride level of the soil and the fluoride content of agricultural products, et al., and, likewise, the relationship between the content of the water and food and the bioavailability of soil fluoride should be elucidated.

\section{CONCLUSIONS}

1. The distribution of T-F contents in the plough layer $(0-20 \mathrm{~cm})$ of paddy soils was normally distributed, and Ws-F was fitted for logarithm normal distribution from Hang-Jia-Hu Plain in China. The semivariagrams of T-F was well fitted for the gaussian model, while semivariagrams for logarithm conversion value of soil Ws-F was well fitted for exponential model, respectively. And their Nug/Sill ratios were $23.1 \%$ and $49.9 \%$, respectively. The results suggested that T-F had strong spatial dependence, its spatial variability was mainly controlled by intrinsic factors such as parent material, relives and soil types; Ws-F had moderate spatial dependence, mainly controlled by intrinsic factors and extrinsic factors. The order of range was T-F $>$ Ws-F, indicating T-F in soil had correlation among the whole area and which was mainly affected by parent material.

2. Spatial distribution of the main contents of soil T-F and Ws-F were among $200-300 \mathrm{mg} \mathrm{kg}^{-1}$ and $0.5-1.0 \mathrm{mg} \mathrm{kg}^{-1}$, respectively in the studied area. And what is more, the range of T-F contents in soil was as low as less than $100 \mathrm{mg} \mathrm{kg}^{-1}$ in Yu-hang area accounting for $23.7 \%$ area scale. The range of fluoride contents in the soils from central and eastern parts of Hang-Jia-Hu Plain was higher than that from the western part. The 
soil fluoride concentrations had a close relationship with soil parent material, $\mathrm{pH}$ value, organic matter, CEC and soil texture.

3. The accumulation of fluoride contents in soil was lower in the whole studied area, suggesting that local fluoride epidemic such as dental caries due to lack of fluoride will occur easily in Hang-Jia-Hu Plain in China, so where should be prevented by using fluoridecontaining toothpaste and other effective measure.

\section{ACKNOWLEDGEMENTS}

This research was supported by the Program for Changiiang Scholars and Innovative Research Team in University (PCSIRT) IRT0536 and Foundation of Hangzhou Dianzi University.

\section{REFERENCES}

Atteia. O, Dubois JP, Webster R. 1994 Geostatistical analysis of soil contamination in the Swiss Jura. Environment pollution 86, 315-327.

Bai YL, Li BG, Shi Ych. 1999 Research of the soil salt content distribution and manatement in Huang-Huai-Hai plain based on GIS. Resour Sci 21(4), 66-70.

Baker RL. 1972 Determination of fluoride in vegetation using the specific ion electrode. Anal. Chem 44, 1326.

Cahn MD, Hununel JW, Brouer BH. 1994 Spatial analysis of soil fertility for site-specific crop management. Soil Sci. Soc Am J 58, 1240-1248.

Cambardella CA, Moorman TB, Novak JM, Parkin TB, Turco RF, Konopka AE. 1994 Fieldscale variability of soil properties in central lowa soils. Soil Sci Soc Am J 58, 1501-1511.

Chien YL, Lee DY, Guo HY, Houng KH. 1997 Geostatistical analysis of soil properties of mid-west Taiwan soils. Soil Sci 162, 291-297.

China Environment Monitoring General Station. 1990 The background values of Elements in Soils in China. China Environment Science Press, Beijing (in Chinese).

Cressie C. 1990 The origins of kriging. Math Geo 22(2), 239-252.

Fejeskov O, Larsen MJ, Rrchards A, and Baelum V. 1994 Dental tissue effects of fluoride. Adv. Dent. Res 8, 15-31.

Fisher E, Thornton B, Hudson G. 1998 The variability in total and extractable soil phosphorus under a grazed pasture. Plant and Soil 203, 249-255.

Fung KF, Zhang ZQ, Wong JWC, Wong MH. 1999 Fluoride contents in tea and soil from tea plantations and the release of fluoride into tea liquor during infusion. Environmental Pollution 104, 197-205.

Geeson NA, Abrahams PW, Murphy MP, Thornton I. 1998 Fluorine and metal enrichment of soils and pasture herbage in the old mining areas of Derbyshire, UK. Agriculture, Ecosystems and Environment 68, 217-231. 
Goovaerts P. 1999 Geostatistics in soil science: state-of-the-art and perspectives. Geoderma $89,1-45$.

Guo XD, Fu BJ, Ma KM, Chen LD. 2000 Spatial variability of soil nrttients based on geostatistics combined with GIS - A case study in Zunhua City of Hebei Province. Chinese Journal of Applied Ecology 11(4), 557-563 (in Chinese).

Honrner JM, Bell JNB. 1995 Evolution of fluoride tolerance in Plantago lanceolata. The Science of the Total Environment 159, 163-168.

Hu KL, Zhang FR, Lv YZ, Wang R, Xu Y. 2004 Spatial distribution of concentrations of soil heavy metals in Daxing county, Beijing. Acta scientiae circumstantiae 24(3), 463-468 (in Chinese).

Isaaks EH, Srivastava RM. 1989 An introduction to applied geostatistics. Oxford University Press, New York.

Li YH, Wang WY, Luo KL. 2004 Distribution of selenium and fluoride in soils of Daba mountains. Acta pedologica sinica 41(1), 61-67 (in Chinese).

Liu XM, Xu JM, Zhang MK, Shi Z, Shi JC. 2003 Study on spatial variability of soil nutrients in Taihu lake region - a case of Pinghu City in Zhejiang Province. Journal of Zhejiang University (Agric. and Life Sci.) 29, 76-82 (in Chinese).

Marian Kjellevold Malde, Amund Maage, Elizabeth Macha, Kare Julshamn, and Kjell Bjorvatn. 1997 Fluoride content in selected food items from five areas in East Africa. Journal of food composition and analysis 10, 233-245.

Mendonca Santos ML, Guenat C, Bouzelboudjen M, Golay F. 2000 Three-dimensional GIS cartography applied to the study of the spatial variation of soil horizons in a Swiss floodplain. Geoderma 97, 351-366.

Nanjing Agricultural Unviersity. 1981 Analytical Methods for Soil and Agricultural Chemistry. Agriculture Press, Beijing, pp. 29-39 (in Chinese).

Romic M, Romic D. 2003 Heavy metals distribution in agricultural topsoils in urban area. Environ Geo 43, 795-805.

Singh B, Dass J. 1993 Occurrence of high fluoide in groundwater of Haryana. Bhujal News 8(1), 28-31.

Sokal RR, Rohlf FJ. 1981 Biometry, 2nd Edn. WH Freeman and Company, New York.

Steiger B von, Webster R, Schulin R, Lehmann R. 1996 Mapping heavy metals in polluted soil by disjunctive kriging. Environ Pollu 94(2), 205-215.

Tsegaye T, Rovert L Hill. 1998 Intensive tillage effects on spatial variability of soil test: plant growth and nutrient uptake measurements. Soil Science 13(2), 155-165.

Underwood EJ, Mertz W. 1987 Introduction. In Trace Elements in Human and Animal Nutrition (W. Mertz, Ed.), 5th ed. Academic Press, San Diego, pp. 1-19.

Villa AE. 1979 Rapid method for determining fluoride in vegetation using an ion-selective electrode. Analyst 104, 545-551.

Wang ZQ. 1999 Geostatistics and its application in ecology. Science Press, Beijing, China, pp. 162-192 (in Chinese).

Wheeler SM, Fell LR. 1983 Fluorides in cattle nutrition. Commonwealth Bureau of Nutrition, Nutition Abstracts and Reviews, Series B, 53, No. 12. Commonwealth Agricultural Bureaux, Farnham Royal, Bucks, pp. 741-767.

White JG, Welch RM, Norvell WA. 1997 Soil zinc map of the USA using geostatistics and geographic information system. Soil Sci Soc Am J 61, 185-194.

Xie ZM, Wu WH, Xu JM. 2003 Study on fluoride emission from soils at high temperature related to brick-making process. Chemosphere 50, 763-769. 
Xie ZM, Ye ZH, Wong MH. 2001 Distribution characteristics of fluoride and aluminum in soil profiles of an abandoned tea plantation and their uptake by six woody species. Environment International 26, 341-346.

Yu Pin Lin, Tsun Kuo Chang, Tung Po Teng. 2000 Characterization of soil lead by comparing sequential Gaussian simulation, simulated annealing simulation and kriging methods. Environ Geo 11 41, 189-199. 